\title{
JOB SATISFACTION, SERVICE QUALITY AND THE CUSTOMER SATISFACTION IN THE IT SECTOR OF KARACHI
}

\author{
Muhammad Muzammil Ghayas ${ }^{1}$ and Javed Hussain ${ }^{2}$ \\ ${ }^{1}$ PhD Scholar, Iqra University, PAKISTAN, muzzammilghayas87@gmail.com \\ 2 Dean, Iqra University, PAKISTAN, drjaved@iqra.edu.pk
}

\begin{abstract}
This research investigates the relationship between the job satisfaction and the customer satisfaction. Data were collected from 316 employees of IT sector who works for the support contracts and their respective contact persons of the clients they work for. Hence there were 632 respondents in all. Structural Equation Modeling (SEM) was used as the statistical technique. Results indicate that all eight job satisfaction facets studied in the research have significant positive impact on Customer Satisfaction and the Service Quality. Moreover, it is also found that the Service Quality partially mediates the relationship between all the studied job satisfaction facets and the Customer satisfaction.
\end{abstract}

Keywords: Job Satisfaction, Customer Satisfaction, Service Quality, IT Sector, Karachi.

\section{INTRODUCTION}

Customer satisfaction has always been a topic of discussion for the marketers. Marketers have tried to raise the levels of customer satisfaction in every era to remain competitive. A century or two ago, the level of customer satisfaction could have been increased with the help of declining prices but the introduction of the globalization and the technological advancements of the twenty first century has changed the world in a dramatic manner. The business world has been affected by these dramatic changes too and the business world that once used to predominantly revolve around the products is now in principle revolves around the services.

The service industry grew at a tremendous pace in the twentieth and the twenty first centuries, thus the task of enhancing the customer satisfaction has become more challenging than ever. The marketers in their quest to enhance the customer satisfaction found that it is the service quality that can enhance the level of the customer satisfaction and hence they started to look for the ways of enhancing the level of service quality. The researchers in the field of Human Resources asserted that it is the job satisfaction that can be helpful in increasing the service quality and hence the marketers started to found the much needed answer of the customer satisfaction through the job satisfaction. A number of researchers e.g. Wangenheim, (2007); Chi and Gursoy (2009); Naeem (2013) and Kermani (2013) confirmed the positive association between the job satisfaction and the customer satisfaction. Once it is established that job satisfaction has positive impact on customer satisfaction, researchers then started their quest to establish that if it is really the service quality that mediates the relationship between job satisfaction and the customer satisfaction. Hence this study aims to explain relationship between the job satisfaction and the customer satisfaction and the role that service quality plays in the relationship between the two variables. Moreover two new variable of job satisfaction namely the 
positive health benefits and the educational enhancement opportunities were also added in the research along with the previously studied facets of the job satisfaction.

\section{LITERATURE REVIEW}

Ashraf, Joarder and Al-Masum (2008) proposed significant correlation between the compensation and job satisfaction. Gallardo, Sanchez-Canizares, Lopez-Guzman, and Jesus (2010) also suggest compensation being correlated with job satisfaction. Malik, Nawab, Naeem and Danish (2010) also included compensation as the facet of job satisfaction in their study.

Ghayas and Siddiqui (2012) used communication as a job satisfaction facet while studying turnover intentions in the pharmaceutical industry of Pakistan. Ali and Haider (2012) also asserted that the dimensions of communication are significantly associated with job satisfaction. While studying the banking sector, Saleem, Majeed, Aziz and Usman (2013) supported the argument of communication being a significant predictor of job satisfaction.

While examining the teaching staff, Saba (2011) argued that the co-workers' support is a determinant of job satisfaction. Kabir and Parvin (2011) also supported the arguments of co-workers support being significantly influenced correlated with the job satisfaction. Ghayas and Siddiqui (2012) also used co-workers' support as a facet of job satisfaction.

Lam, Baum and Pine (2001) found correlation between the nature of work and the job satisfaction. Chen (2006) also argued that the nature of work is a facet of job satisfaction. Salleh, Nair and Harun (2012) also asserted that nature of work is a determinant of job satisfaction.

Al-Ahmadi (2002) proposed that supervision is a facet of job satisfaction. Chen (2006) also advocates that supervision is a facet of job satisfaction. Mosadeghrad, Ferlie and Rosenberg (2008) also used supervision as a job satisfaction facet while examining job satisfaction of Hospital Employees. Malik et al. (2010) also used supervision as a job satisfaction facet.

Joseph, $\mathrm{Ng}$, Koh, and Ang, (2007) advocates the presence of correlation between promotional opportunities and job satisfaction. Azeem (2010) also used PO as job satisfaction facet.

Wangenheim (2007) suggested positive association between job satisfaction and customer satisfaction. Chi and Gursoy (2009) advocated the presence of causal relationship between the two variables. Naeem (2013) suggested the presence of correlation between the JS and the CS. Kermani (2013) also found that JS has significant impact on the CS. Amoopour et al. (2014) also supported the arguments of positive relationship between the two variables.

\section{METHODOLOGY}

\subsection{Instrument and Measures}

Two separate questionnaires were used for the research; the first survey was used to collect the data for measuring the job satisfaction the employees of the IT Sector of Pakistan. Whereas the second questionnaire was used to measure the customer satisfaction of the contact persons of the respective clients for that the IT Sector employees were providing services for.

The first questionnaire that was used for measuring the facets of the job satisfaction was comprised of 32 items, out of these 32 items 24 items were adapted and contextualized from Paul Spector's Job Satisfaction Survey and were used to measure six out of the eight independent variables. Whereas eight additional items were developed to measure the two independent variables namely Positive Health Benefits $(\mathrm{PHB})$ and the Educational Enhancement Opportunities (EEO).

The second questionnaire was used for measuring the Service Quality and the Customer Satisfaction was developed. The questionnaire consists of eight items other than the questions to gather demographic data. Four items were developed to measure the mediating variable Service Quality and the rest of the four were developed for measuring the dependent variable Customer Satisfaction in the IT sector.

\subsection{Sample and Data Collection}

Purposive sampling used and the data was collected only from those employees of the IT sector of Karachi who work for support contract and their respective clients. A total of 350 pair of questionnaires (700 questionnaires) were distributed for the survey to the employees of the IT Sector and their respective clients. 
340 IT Sector Employees and 323 IT Sector clients returned the filled questionnaires and there were a total of 316 pairs of filled questionnaires that were received from both the IT sector employees and their clients.

\subsection{Statistical Model}

Two statistical models were made to test the hypotheses. The first model was a structural model that was used to test the impact of various JS facets on mediating variable SQ and the CS. The relationship between the mediating variable SQ and the CS was also tested in the same model. Moreover the mediating effect was also calculated from this model.

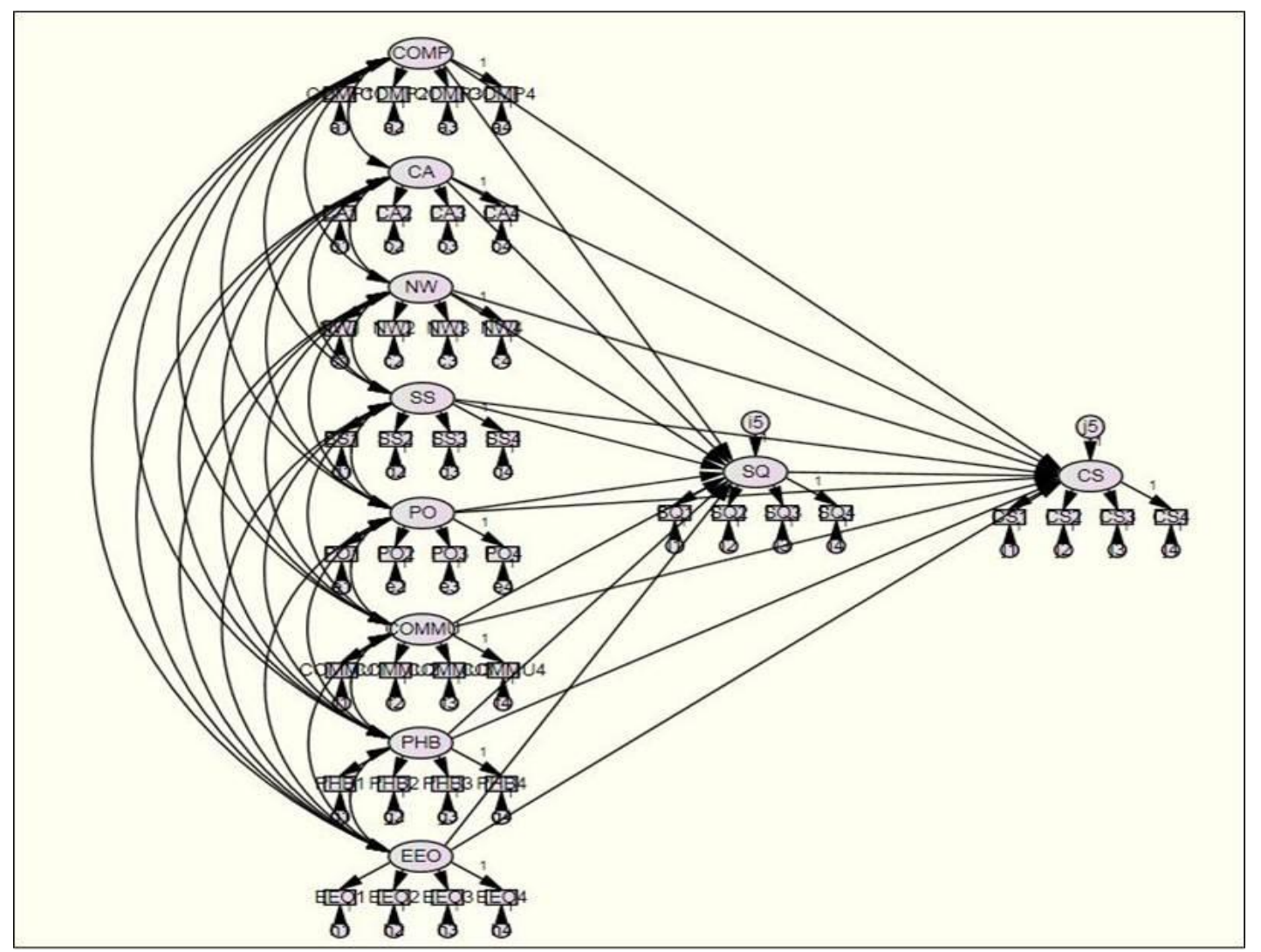

Whereas in the second model was used to test the type of mediation, the second model was an amended version of the first model in which the mediating variable service quality was removed. Hence the purpose of the model was to calculate the impact of the facets of job satisfaction on the customer satisfaction in the absence of the mediating variable service quality.

\section{RESULTS}

\subsection{Model Fit}

SEM is used to test the hypotheses. The model fit is measured through the various criteria that are used to measure the model adequacy of the structural model. Byrne (1989) suggest that the value of CMIN/df should be less than 2 in order to consider a model statistically fit. In this research the CMIN/df value for the model is 1.035 which is well below the cutoff value of 2 . The $p$-value of the CMIN is 0.255 hence we fail to reject the null hypotheses of model being statistically fit. The Goodness of Fit Index (GFI) is 0.902 which is above the acceptable value of 0.90 . The NFI value is 0.960 , the CFI value is 0.999 , whereas the RMSEA value is 0.011 . Hence all the indicators suggest that the model is statistically fit.

The sample size for the research is 316 . HOELTER's critical $N$ for the significance level of 0.05 indicates the largest sample for which the model with the calculated chi-square and the given degrees of freedom should be accepted. The HOELTER's critical $\mathrm{N}$ for the data was 332 which indicates that results of the structural modeling are valid if the sample size is 332 or less. Since in this study the sample size was 316 , hence it indicates that there was no issue of sample size while conducting the research. 


\subsection{Confirmatory Factor Analysis}

Confirmatory Factor Analysis was applied to the responses that were collected through first questionnaire which was used to measure the job satisfaction. Eight factors of job satisfaction namely compensation, coworkers' attitude, nature of work, supervisor's support, promotional opportunities, communication, positive health benefits and educational enhancement opportunities were confirmed through the confirmatory factor analysis.

\begin{tabular}{|c|c|}
\hline \multicolumn{2}{|c|}{ CFA for Compensation } \\
\hline Item \# & Factor Loading \\
\hline 1 & 0.961 \\
\hline 2 & 0.943 \\
\hline 3 & 0.943 \\
\hline 4 & 0.923 \\
\hline
\end{tabular}

Item 3 and 4 were reverse coded. The Cronbach alpha value for compensation was 0.969 which indicates that the measures are reliable.

\begin{tabular}{|c|c|}
\hline \multicolumn{2}{|c|}{ CFA for Coworkers' Attitude } \\
\hline Item \# & Factor Loading \\
\hline 5 & 0.962 \\
\hline 6 & 0.964 \\
\hline 7 & 0.927 \\
\hline 8 & 0.928 \\
\hline
\end{tabular}

Item 7 and 8 were reverse coded. The Cronbach alpha value for co-workers' attitude was 0.971 which indicates that the measures are reliable.

\begin{tabular}{|c|c|}
\hline \multicolumn{2}{|c|}{ CFA for Nature of Work } \\
\hline Item \# & Factor Loading \\
\hline 9 & 0.960 \\
\hline 10 & 0.956 \\
\hline 11 & 0.934 \\
\hline 12 & 0.933 \\
\hline
\end{tabular}

Item 9 was reverse coded. The Cronbach alpha value for nature of work was 0.971 which indicates that the measures are reliable.

\begin{tabular}{|c|c|}
\hline \multicolumn{2}{|c|}{ CFA for Supervisor's Support } \\
\hline Item \# & Factor Loading \\
\hline 13 & 0.963 \\
\hline 14 & 0.955 \\
\hline 15 & 0.932 \\
\hline 16 & 0.956 \\
\hline
\end{tabular}

Item 14 and 16 were reverse coded. The Cronbach alpha value for supervisor's support was 0.974 which indicates that the measures are reliable.

\begin{tabular}{|c|c|}
\hline \multicolumn{2}{|c|}{ CFA for Promotional Opportunities } \\
\hline Item \# & Factor Loading \\
\hline 17 & 0.952 \\
\hline 18 & 0.935 \\
\hline 19 & 0.934 \\
\hline 20 & 0.951 \\
\hline
\end{tabular}

Item 17 was reverse coded. The Cronbach alpha value for promotional opportunities was 0.970 which indicates that the measures are reliable. 


\begin{tabular}{|c|c|}
\hline \multicolumn{2}{|c|}{ CFA for Communication } \\
\hline Item \# & Factor Loading \\
\hline 21 & 0.950 \\
\hline 22 & 0.942 \\
\hline 23 & 0.941 \\
\hline 24 & 0.937 \\
\hline
\end{tabular}

The Cronbach alpha value for communication was 0.970 which indicates that the measures are reliable.

\begin{tabular}{|c|c|c|}
\hline \multicolumn{3}{|c|}{ CFA for Positive Health Benefits } \\
\hline $\begin{array}{l}\text { Item } \\
\#\end{array}$ & Statements & $\begin{array}{l}\text { Factor } \\
\text { Loading }\end{array}$ \\
\hline 25 & $\begin{array}{l}\text { The company focuses on providing the facilities that have positive } \\
\text { consequences on employee health. }\end{array}$ & 0.962 \\
\hline 26 & $\begin{array}{l}\text { The company tends to eliminate anything that has negative consequences on } \\
\text { employee health. }\end{array}$ & 0.949 \\
\hline 27 & $\begin{array}{l}\text { The company encourages the employees to use facilities provided in the } \\
\text { company for being healthy. }\end{array}$ & 0.941 \\
\hline 28 & $\begin{array}{c}\begin{array}{l}\text { There are not many facilities in the company that can positively influence the } \\
\text { health of employees. }\end{array} \\
\text { ( }\end{array}$ & 0.948 \\
\hline
\end{tabular}

Item 28 was reverse coded. The Cronbach alpha value for positive health benefits was 0.973 which indicates that the measures are reliable.

\begin{tabular}{|c|c|c|}
\hline \multicolumn{2}{|c|}{ CFA for Educational Enhancement Opportunities } \\
$\begin{array}{c}\text { Item } \\
29\end{array}$ & Statements & $\begin{array}{c}\text { Factor } \\
\text { Loading }\end{array}$ \\
\hline 30 & In this company, I have the opportunities to learn new techniques and technologies. & 0.950 \\
\hline 31 & The company provides flexible timings for those who study/take classes. & 0.941 \\
\hline 32 & The company provides monetary benefits/loans for study purpose. & 0.942 \\
\hline & $\begin{array}{c}\text { The company does not reimburse the tuition fee for the certifications that are } \\
\text { beneficial for future growth of company. } \AA\end{array}$ & 0.956 \\
\hline
\end{tabular}

Item 32 was reverse coded. The Cronbach alpha value for educational enhancement opportunities was 0.972 which indicates that the measures are reliable.

\begin{tabular}{|c|c|c|}
\hline \multicolumn{3}{|c|}{ CFA for Service Quality } \\
\hline Item \# & Statements & Factor Loading \\
\hline 1 & The Software made by our vendor often crashes. ${ }^{\circledR}$ & 0.959 \\
\hline 2 & Our software vendor responds quickly if the software is crashed. & 0.939 \\
\hline 3 & There are many bugs in the software developed by our vendor. & 0.926 \\
\hline 4 & The vendor usually resolves the issues in a reasonable time. & 0.927 \\
\hline
\end{tabular}

Item 1 of the second questionnaire was reverse coded. The Cronbach alpha value for service quality was 0.966 which indicates that the measures are reliable.

\begin{tabular}{|c|c|c|}
\hline \multicolumn{2}{|c|}{ CFA for Customer Satisfaction } \\
\hline $\begin{array}{c}\text { Item } \\
\#\end{array}$ & Statements & $\begin{array}{c}\text { Factor } \\
\text { Loading }\end{array}$ \\
\hline 5 & I feel the services provided by our vendor are up to the mark. & 0.957 \\
\hline 6 & I am overall happy with the performance of our software vendor. & 0.940 \\
\hline 7 & I think we should change our software vendor. 8 & 0.933 \\
\hline 8 & If I have to recommend a software vendor to someone else, I will recommend our \\
software vendor. & 0.947 \\
\hline
\end{tabular}

Item 7 of the second questionnaire was also reverse coded. The Cronbach alpha value for customer satisfaction was 0.970 which indicates that the measures are reliable. 


\subsection{Job Satisfaction Facets and Customer Satisfaction}

Hypotheses one to eight deal with the causal relationship between Job Satisfaction facets and Customer Satisfaction. Null hypothesis of the hypotheses one to eight assumes the absence of any significant causal relationship between Job Satisfaction facets and the Customer Satisfaction. These causal relationships are tested through the structural model. Results of structural model are given in below table:

\begin{tabular}{|c|c|c|c|c|}
\hline Hypothesis \# & $\begin{array}{c}\text { Causal } \\
\text { Relationship }\end{array}$ & $\boldsymbol{\beta}$ Estimate & $\boldsymbol{p}$-value & Null Hypothesis \\
\hline 1 & COMP - CS & 0.094 & 0.047 & Rejected \\
\hline 2 & CA - CS & 0.098 & 0.037 & Rejected \\
\hline 3 & NW - CS & 0.099 & 0.043 & Rejected \\
\hline 4 & SS - CS & 0.108 & 0.013 & Rejected \\
\hline 5 & PO - CS & 0.097 & 0.036 & Rejected \\
\hline 6 & COMMU - CS & 0.096 & 0.042 & Rejected \\
\hline 7 & PHB - CS & 0.100 & 0.030 & Rejected \\
\hline 8 & EEO - CS & 0.099 & 0.027 & Rejected \\
\hline
\end{tabular}

Since the $\beta$ coefficients for all variables are positive and $p$-value for all the relationships are less than 0.05 therefore we reject the null hypotheses of hypothesis 01 to hypothesis 08 and conclude that all the Job Satisfaction facets included have significant and positive impact on Customer Satisfaction.

\subsection{Service Quality and Customer Satisfaction}

The ninth hypothesis is used to test causal relationship between the mediating variable Service Quality and the dependent variable Customer Satisfaction.

\begin{tabular}{|c|c|c|c|c|}
\hline Hypothesis \# & $\begin{array}{c}\text { Causal } \\
\text { Relationship }\end{array}$ & $\boldsymbol{\beta}$ Estimate & $\boldsymbol{p}$-value & Null Hypothesis \\
\hline 9 & SQ-CS & 0.440 & 0.000 & Rejected \\
\hline
\end{tabular}

The $\beta$ coefficient is 0.440 and its $p$-value is 0.000 which indicates that the Service Quality has significant positive impact on the Customer Satisfaction.

\subsection{Job Satisfaction Facets and Service Quality}

Hypotheses tenth to seventeenth deals with the causal relationship between JS facets and the mediating variable Service Quality. Null hypotheses assume the absence of any significant relationship between Job Satisfaction facets and the mediating variable Service Quality. These causal relationships are tested through the structural model. Results of structural model are given in the below table:

\begin{tabular}{|c|c|c|c|c|}
\hline Hypothesis \# & $\begin{array}{c}\text { Causal } \\
\text { Relationship }\end{array}$ & $\boldsymbol{\beta}$ Estimate & p-value & Null Hypothesis \\
\hline 10 & COMP - SQ & 0.142 & 0.005 & Rejected \\
\hline 11 & CA - SQ & 0.125 & 0.013 & Rejected \\
\hline 12 & NW - SQ & 0.110 & 0.039 & Rejected \\
\hline 13 & SS - SQ & 0.102 & 0.033 & Rejected \\
\hline 14 & PO - SQ & 0.120 & 0.017 & Rejected \\
\hline 15 & COMMU - SQ & 0.165 & 0.001 & Rejected \\
\hline 16 & PHB - SQ & 0.128 & 0.010 & Rejected \\
\hline 17 & EEO - SQ & 0.110 & 0.023 & Rejected \\
\hline
\end{tabular}

Since the $\beta$ coefficients for all the relationships are positive and the $p$-values are less than 0.05 therefore we reject the null hypotheses from hypothesis 10 to hypothesis 17 and conclude that studied Job Satisfaction facets have significant and positive impact on Service Quality.

\subsection{Mediating Effect of Service Quality}

Null hypothesis of hypotheses eighteen to twenty five asserts that Service Quality does not mediate relationship between the facets of Job Satisfaction and the Customer Satisfaction. These hypotheses were tested using the Bootstrapping method with 1000 bootstrap samples. The bootstrapping technique provides the researchers with the Standard Indirect Effect of predictor on criterion through the Mediator. The method also provides the upper and the lower bounds of the confidence intervals for the Standard Indirect Effect. If the 
Standard Indirect Effect lies between the confidence interval, we reject the null hypothesis of Indirect Effect of predictor on criterion being equal to zero which in turn suggests the presence of mediating effect of the mediating variable between the independent and the dependent variables.

\begin{tabular}{|c|c|c|c|c|c|c|}
\hline $\begin{array}{c}\text { Hypothesis } \\
\#\end{array}$ & $\begin{array}{c}\text { Indirect Effect / Mediation } \\
\text { through SQ }\end{array}$ & SIE & $\begin{array}{c}\text { Upper } \\
\text { Bound }\end{array}$ & $\begin{array}{c}\text { Lower } \\
\text { Bound }\end{array}$ & $\begin{array}{c}\text { p- } \\
\text { value }\end{array}$ & $\begin{array}{c}\text { Null } \\
\text { Hypothesis }\end{array}$ \\
\hline 18 & COMP - SQ - CS & 0.063 & 0.007 & 0.195 & 0.035 & Rejected \\
\hline 19 & CA - SQ - CS & 0.055 & 0.003 & 0.196 & 0.042 & Rejected \\
\hline 20 & NW - SQ - CS & 0.047 & 0.014 & 0.199 & 0.028 & Rejected \\
\hline 21 & SS - SQ - CS & 0.048 & 0.028 & 0.196 & 0.006 & Rejected \\
\hline 22 & PO - SQ - CS & 0.054 & 0.006 & 0.184 & 0.032 & Rejected \\
\hline 23 & COMMU - SQ - CS & 0.073 & 0.003 & 0.190 & 0.041 & Rejected \\
\hline 24 & PHB - SQ - CS & 0.058 & 0.007 & 0.191 & 0.044 & Rejected \\
\hline 25 & EEO - SQ - CS & 0.051 & 0.010 & 0.189 & 0.022 & Rejected \\
\hline
\end{tabular}

The above table indicates the Standard Indirect Effects (SIE), the lower and the upper bounds of the confidence intervals for the SIE and the p-value for the SIE. Cheung and Lau (2008) suggested the presence of mediation if the SIE lies between the SIE confidence interval and is significant. The above table indicates that the Standard Indirect Effect (SIE) values of all the job satisfaction facets on customer satisfaction through the mediating variable service quality lies between the confidence interval and are significant therefore it is concluded that the service quality mediates the relationship between studied Job Satisfaction facets and the Customer Satisfaction.

\subsection{Full Mediation versus Partial Mediation}

If the relationship between the predictor and the criterion was significant in the absence of mediator and becomes insignificant after adding the mediator, the mediation is said to be the full mediation. However if the relationship remains significant but with the reduced $\beta$ coefficients after adding the mediator, the mediation is known as the partial mediation

We tested the mediation type by making an additional structural model in which the mediator was removed. The CMIN/df value for the model was 0.878 which is well below the cutoff value of 2 . The $p$-value of the CMIN was 0.982 , the GFI value was 0.922 , the NFI value was 0.970 , the CFI value was 1.000 and the RMSEA value was 0.000 . The HOELTER's critical $N$ for the data was 395 or less. Hence the model was statistically fit.

\begin{tabular}{|c|c|c|c|c|c|}
\hline Hypothesis \# & $\begin{array}{c}\text { Causal } \\
\text { Relationship }\end{array}$ & $\begin{array}{c}\boldsymbol{\beta} \text { Estimate in } \\
\text { the absence of } \\
\text { Mediator }\end{array}$ & $\begin{array}{c}\mathbf{p} \text {-value in } \\
\text { the absence } \\
\text { of Mediator }\end{array}$ & $\begin{array}{c}\boldsymbol{\beta} \text { Estimate in } \\
\text { the presence } \\
\text { of Mediator }\end{array}$ & $\begin{array}{c}\text { p-value in } \\
\text { presence of } \\
\text { Mediator }\end{array}$ \\
\hline 1 & COMP-CS & 0.156 & 0.002 & 0.094 & 0.047 \\
\hline 2 & CA - CS & 0.153 & 0.003 & 0.098 & 0.037 \\
\hline 3 & NW - CS & 0.147 & 0.006 & 0.099 & 0.043 \\
\hline 4 & SS - CS & 0.153 & 0.001 & 0.108 & 0.013 \\
\hline 5 & PO-CS & 0.150 & 0.003 & 0.097 & 0.036 \\
\hline 6 & COMMU - CS & 0.169 & 0.001 & 0.096 & 0.042 \\
\hline 7 & PHB - CS & 0.156 & 0.002 & 0.100 & 0.030 \\
\hline 8 & EEO-CS & 0.148 & 0.003 & 0.099 & 0.027 \\
\hline
\end{tabular}

The $\beta$ coefficients and the $p$-values in the absence and the presence of the mediating variable Service Quality were compared to test if the mediation was the full mediation or the partial mediation. Since the $p$-values of all the eight causal relationships were less than 0.05 therefore the absence of full mediation is suggested. Moreover the $\beta$ coefficients of all the eight facets of Job Satisfaction in their causal relationship with the Customer Satisfaction were greater in absence of the mediating variable than the $\beta$ coefficients in the presence of the mediating variable therefore it is concluded that the service quality partially mediates relationship between Job Satisfaction facets and the Customer Satisfaction.

\section{CONCLUSION}

Results indicate that all the facets of the job satisfaction namely have significant impact on both the service quality and the customer satisfaction. In this study, two new determinants of job satisfaction namely positive health benefits and the educational enhancement opportunities were also included with the other previously 
studied facets of job satisfaction. These facets are also found to have significant positive impact on both the service quality and the customer satisfaction. Therefore, it is recommended that Human Resource professionals in the IT sector must also focus on positive health benefits and the educational enhancement opportunities as well with the other previously known facets of job satisfaction in their quest to increase the level of employee satisfaction.

Moreover it is also found that service quality mediates relationship between studied the job satisfaction facets and the customer satisfaction. It is thereby concluded that in order to remain competitive especially in the service oriented businesses managers must focus on enhancing the level of job satisfaction of the employees to enhance the level of service quality which in turn will be helpful in enhancing the level of the customer satisfaction. Hence it is concluded that the increasing the level of employee satisfaction is the key to increase the level of customer satisfaction in the IT sector of Karachi.

\subsection{Recommendations for Future Research}

Since the research was conducted only in the IT sector and was limited to the geographical limits of Karachi city therefore in order to make the research generalizable researchers should conduct similar researches in other geographical locations.

\section{REFERENCE LIST}

Al-Ahmadi, H.A. (2002). "Job Satisfaction of Nurses in Ministry of Health Hospitals in Riyadh". Saudi Medical Journal. Vol. 23(6): 645-650.

Ali, A., and Haider, J. (2012). "Impact of inter organizational communications on employee job satisfaction Case of some Pakistani Banks". Global Advanced Research Journal of Management and Business Studies. Vol. 1(10): 38-44.

Amoopour, M., Hemmatpour, M., and Mirtaslimi, S, S. (2014). "Job Satisfaction of Employee and Customer Satisfaction”. Arabian Journal of Business and Management Review. Vol. 3(6): 1-6.

Ashraf, M.A., Joarder, M.H., and Al-Masum, R. (2008). "Job Satisfaction of Employees in the Mobile Phone Corporates in Bangladesh: A Case Study". Working Paper Series. Vol. 22(1), 1-16.

Azeem, S.M. (2010). "Job Satisfaction and Organizational Commitment among Employees in the Sultanate of Oman”. Psychology. Vol. 1, 295-299.

Byrne, B.M. (2010). Structural Equation Modeling Using AMOS: Basic Concepts, Applications, and Programming. Taylor and Francis Group.

Chen, C.F. (2006). "Job satisfaction, organizational commitment and flight attendants' turnover intentions: A note". Journal of Air Transport Management. Vol. 12, 274-276.

Cheung, G.W., and Lau, R.S. (2008). "Testing Mediation and Suppression Effects of Latent Variables: Bootstrapping with Structural Equation Models". Organizational Research Methods. Vol. 11(2), 296-325.

Chi, G.C. and Gursoy, D. (2009). "Employee Satisfaction, Customer Satisfaction and Financial Performance: An Empirical Examination”. International Journal of Hospitality Management. Vol. 28: 245-253.

Gallardo, E., Sanchez-Canizares, S-M., Lopez-Guzman, T., and Jesus, M.M. (2010). "Employee Satisfaction in the Iberian Hotel Industry". International Journal of Contemporary Hospitality Management. Vol. 22(3), 321-334.

Ghayas, M, M., and Siddiqui, S.J. (2012). "Impact of Job Satisfaction on Turnover Intentions in the Pharmaceutical Industry of Karachi". South Asian Journal of Management Sciences. Vol. 6(2): 47-54.

Joseph, D., Ng, K.Y., Koh. C., and Ang, S. (2007). "Turnover of Information Technology Professionals: A Narrative Review, Meta-Analytic Structural Equation Modeling, and Model Development". MIS Quarterly. Vol. 31(3), 547-577.

Kabir, N.M.M., and Parvin, M.M. (2011). "Factors Affecting Employee Job Satisfaction of Pharmaceutical Sector". Australian Journal of Business and Management Research. Vol. 1(9), 113-123.

Kermani, Z, Z. (2013). "A Study of Linking Between Job Satisfaction and Customer Satisfaction: A Case Study of Iran Insurance". Journal of Marketing Development and Competitiveness. Vol. 7(4): 104-109.

Lam, T., Baum, T., and Pine, R. (2001). "Study of Managerial Job Satisfaction in Hong Kong's Chinese 
Restaurants". International Journal of Contemporary Hospitality. Vol. 13(1), 35-42.

Malik, M.E., Nawab, S., Naeem, B., and Danish, R.Q. (2010). "Job Satisfaction and Organizational Commitment of University Teachers in Public Sector of Pakistan". International Journal of Business and Management. Vol. 5(6), 17-26.

Mosadeghrad, A.M., Ferlie, E. and Rosenberg, D. (2008). "A study of the Relationship between Job Satisfaction, Organizational Commitment and Turnover Intention among Hospital Employees". Health Services Management Research. Vol. 21: 211-227.

Naeem, A. (2013). "Impact of Employee Empowerment, Job Satisfaction and Organizational Commitment on Customer Satisfaction". International Journal of Modern Business Issues of Global Market. Vol. 1(1): 2838.

Wangengiem, F.V., Evanschitzky, H. and Wunderlich, M. (2007). "Does The Employee-Customer Satisfaction Link Hold For All Employee Groups?”. Journal of Business Research. Vol. 60: 690-697.

Saba, I. (2011). "Measuring the Job Satisfaction Level of the Academic Staff in Bhawalpur Colleges". International Journal of Academic Research in Business and Social Sciences. Vol. 1(1).

Saleem, S., Majeed, S., Aziz, T., and Usman, M. (2013). "Determinants of Job Satisfaction among Employees of Banking Industry at Bahawalpur". Journal of Emerging Issues in Economics, Finance and Banking. $1(2), 150-162$.

Spector, P.E. (1985). "Measurement of Human Service Staff Satisfaction: Development of the Job Satisfaction Survey". American Journal of Community Psychology. Vol. 13(6), 691-713.

Westlund, S.G., and Hannon, J.C. (2008). "Retaining Talent: Assessing Job Satisfaction Facets Most Significantly Related to Software Developer Turnover Intentions". Journal of Information Technology Management. Vol. 19(4), 1-15. 